\title{
What controls the oceanic dimethylsulfide (DMS) cycle? A modeling approach
}

\author{
K. D. Six ${ }^{1}$ and E. Maier-Reimer ${ }^{1}$ \\ Received 12 January 2006; revised 10 July 2006; accepted 27 July 2006; published 22 November 2006.
}

[1] We implemented a process-based DMS module into the global carbon cycle ocean model (HAMOCC5) which includes a simple module for plankton dynamics and investigated the regional and seasonal variations of the marine sulfur cycle. The turnover rates within the DMS cycle are only poorly known. Therefore we developed, on the basis of a global DMS data set, an optimization routine for the free parameters controlling DMS production and removal. The resulting seasonal and regional distributions of DMS concentration are fully consistent with the underlying hydrodynamical and biogeochemical processes. We investigated a series of DMS model approaches with various complexities. The distinction between different DMS producing phytoplankton species and the consideration of the regionally and seasonally varying bacterial activity on converting dDMSP to DMS and on DMS consumption appears to have a crucial effect on the quality of the results in the given model conception.

Citation: Six, K. D., and E. Maier-Reimer (2006), What controls the oceanic dimethylsulfide (DMS) cycle? A modeling approach, Global Biogeochem. Cycles, 20, GB4011, doi:10.1029/2005GB002674.

\section{Introduction}

[2] The role of sulfur in influencing the radiative forcing of the Earth is a topic of vivid discussion. Sulfur aerosol particles have a direct impact on the backscattering properties of the atmosphere. Additionally, they may act as cloud condensation nuclei and thus have an indirect impact on the radiation budget of the Earth. Simulated patterns of global mean air temperature change are in better agreement with the observed atmospheric temperature increase over the past decade when taking into account radiative forcing from anthropogenic sulfur emissions [Roeckner et al., 1999; Bengtsson et al., 1999]. These studies face the problem that for the oceanic boundary forcing neither the natural sulfur flux distribution nor its changes with climate variations are not well understood. In view of the ocean being the largest natural sulfur source and an anthropogenic sulfur emission estimated to about twice the natural one (for year 2000 [Intergovernmental Panel on Climate Change, 2001]) this uncertainty on the oceanic DMS cycle is unsatisfactory.

[3] Several attempts have been made to estimate the global natural sulfur emission of the ocean. All of them have in common that the surface concentrations are calculated from a correlation of DMS to variables as, for example, chlorophyll, solar radiation, nutrients, biological provinces or mixed layer depths [Anderson et al., 2001; Simó and Dachs, 2002; Belviso et al., 2004]. Kettle et al. [1999] compiled a comprehensive data set of DMS surface concentration containing more than 15,000 measurements. On the basic assumption that similar biological conditions

\footnotetext{
${ }^{1}$ Max-Planck Institute for Meteorology, Hamburg, Germany.
}

Copyright 2006 by the American Geophysical Union. 0886-6236/06/2005GB002674\$12.00 yield the same DMS concentration and seasonality, they divided the ocean into 57 biological provinces [Longhurst et al., 1995], used a simple apportioning scheme to generate monthly maps to DMS surface concentration and calculated a global annual oceanic DMS flux to the atmosphere between 19 and $40 \mathrm{Tg} \mathrm{S} / \mathrm{yr}$ depending on the gas exchange parameterization. Anderson et al. [2001] got similar results for the oceanic DMS flux using a regression of DMS to chlorophyll, nutrients, and solar radiation. On the basis of a nonlinear regression between chlorophyll, silicate and DMS deduced from measurements in the North Atlantic Aumont et al. [2002] predicted surface DMS concentrations using tracer distributions taken from a global biogeochemical ocean model.

[4] These attempts all suffer from the weak correlation between DMS concentration and chlorophyll when established on a global basis [Belviso et al., 2000]. Heterogeneous phytoplankton species assemblages with different spectral absorption qualities of chlorophyll and very different cellular amounts of DMS and DMSP prevent a good regression between DMS and chlorophyll. Furthermore, there is a strong nonlinearity in converting cellular DMSP to DMS in water depending on the phytoplankton assemblage, grazers, and bacterial activity [Levasseur et al., 2004]. In addition, the available DMS measurements are very sparse, especially in regions of the Southern Ocean, so that vague extrapolations in time and space have to be made to compile global seasonal maps of DMS surface concentration. Anderson et al. [2001] stated that the data are not randomly distributed but often taken in biologically active regions with, for example, phytoplankton blooms. This might distort the extrapolation of DMS surface concentration and the calculation of the corresponding flux to the atmosphere. 
[5] The existing process-based DMS models have mostly been applied in one-dimensional studies [e.g., Gabric et al., 1993a; Archer et al., 2004; Le Clainche et al., 2004] and rely on a constant set of turnover rates adjusted for individual geographical locations. The only current application of the DMS model by Gabric et al. [1993a] in a global eddy permitting simulation of the surface ocean was performed by $C h u$ et al. [2003]. With globally and seasonally constant DMS production and consumption rates they underestimated observed DMS concentrations in low latitudes throughout the year and simulated only little seasonal variations between $40^{\circ} \mathrm{S}$ and $40^{\circ} \mathrm{N}$ [Belviso et al., 2004]. Chu et al. [2003] explained deficiencies of their results by the lack of phytoplankton species distinction in DMS production and a constant bacterial consumption rate.

[6] In this paper we present a process-based DMS module implemented into the global three-dimensional HAmburg Model of the Ocean Carbon Cycle (HAMOCC5). The model includes a simple scheme of plankton dynamics which provides the basis for simulations of organic sulfur production. For the prognostic variables, dissolved dimethylsulfoniopropionate (dDMSP) and dimethylsulfide (DMS), we simulate production by various phytoplankton species and bacterial consumption as well as photolysis and flux to the atmosphere for DMS. Turnover processes are related to, for example, local temperatures, solar radiation or substrate concentrations. Their global uniform rates will be adjusted by minimizing a cost function which integrates the difference between model results and observations (DMS data from the revised version by Kettle and Andreae [2000] extended by NOAA, http://saga.pmel.noaa.gov/dms/). The results of the simulation are dynamically consistent maps of DMS surface concentration which are close to the observations, where available. We perform a series of experiments with an increasing complexity of the DMS model. This gives us information about the local and temporal significance of processes controlling the DMS variation. The weakness of such optimization procedures is, of course, always the definition of the global minimum. However, we consider this technique as very promising to get more insight into the oceanic sulfur cycling.

\section{Model Description}

\subsection{Biogeochemical Model}

[7] The DMS cycle was implemented into the HAmburg Model of the Oceanic Carbon Cycle (HAMOCC5) [MaierReimer, 1993; Six and Maier-Reimer, 1996; Aumont et al., 2003] which includes biological production and remineralization of organic matter, and, thus, the relevant processes linked to the DMS cycle. The model includes a description of the iron cycle, but a simpler representation of the opaline production than that of Aumont et al. [2003] (see section 2.2). The basis of our model is the three-dimensional physical ocean general circulation model LSG (large-scale geostrophic [Maier-Reimer et al., 1993]) which provides the hydrodynamical fields for the transport of the oceanic tracers and distribution of temperature and salinity being necessary for the calculation of chemical control variables. The model's horizontal resolution is $3.5^{\circ}$ by $3.5^{\circ}$ and it has 22 levels (two in the first $100 \mathrm{~m}$ ). The model has a realistic but smoothed bottom topography and operates on a monthly time step. Despite the rather coarse spatial and temporal resolution of the model, the major patterns of ocean velocity field are achieved. For testing the quality of the velocity field, distributions of different nonbiological tracers (e.g., $\Delta \mathrm{C} 14, \mathrm{~F}-11$ ) were simulated, resulting in a good agreement between observed and modeled distributions [England and Maier-Reimer, 2001].

[8] The biogeochemical part of the model simulates variations of phosphate, nitrate, ammonium, iron, silicate, organic and inorganic carbon, alkalinity, and oxygen. The time step in the biological model is 3 days in respect to the fast turnover rates involved in biological processes. The advection and dynamics of fast varying biological tracers is iteratively solved to guarantee correspondence in transport to nonbiological tracers. For some tracers gas exchange processes with the atmosphere are considered. To include the effects of a changing mixed layer depth (MLD) on primary production we diagnosed a monthly mean MLD on the basis of the simulated density gradient and the prescribed wind stirring [see also Six and MaierReimer, 1996, Plate 2c]. The MLD affects only the light dependent phytoplankton growth rate and for the DMS cycle the photolysis rate (see section 2.3). The biological scheme in the model has been tuned and validated without DMS. The model, to first order, reproduces the observed global distributions of tracers of the carbon cycle and seasonal variations of $\mathrm{CO}_{2}$, nutrients, and oxygen [Kurz, 1993; Six and Maier-Reimer, 1996]. A substantial discrepancy between model and observations is present in the North Pacific where simulated concentrations are lower than observed concentrations. Simulations of CFC's with the LSG show a reduced upwelling in the North Pacific which results in too low surface phosphate concentration in the model [England and Maier-Reimer, 2001]. The western Equatorial Pacific shows slightly higher than observed phosphate concentrations $(0.3$ instead of $0.15 \mu \mathrm{mol} \mathrm{P} / \mathrm{L})$. The uptake of macronutrients is limited by the very low simulated iron concentrations in this region.

[9] Annual global mean carbon fluxes between the different compartments of the plankton model are shown in Figure 1. All numbers agree well with values given in the literature. The simulated annual net primary production of phytoplankton within the euphotic layer is $41.4 \mathrm{Gt} \mathrm{C}$ (1 Gt $\left.\mathrm{C}=10^{15} \mathrm{~g} \mathrm{C}\right)$. The major fraction of the net primary production $\left(31.0 \mathrm{Gt} \mathrm{C} \mathrm{yr}^{-1}\right)$ serves as food source for zooplankton. The simulated natural senescence of phytoplankton is relatively small $\left(2.2 \mathrm{Gt} \mathrm{yr}^{-1}\right) .8 .1 \mathrm{GtC} / \mathrm{yr}$ are exudated as dissolved organic carbon (DOC).

\subsection{Planktonic Groups}

[10] Keller et al. [1989] report a clear taxonomic pattern which confines major DMS production to dinoflagellates and coccolithophorids. Opal producers like diatoms contain only one tenth (or less) DMSP per cell volume [Keller et al., 1989; Keller, 1991]. A segregation of opal and calcite producing phytoplankton is, therefore, necessary for simulations of DMS. Concentrations of diatoms and coccolithophorids are introduced as new prognostic variables. The net 


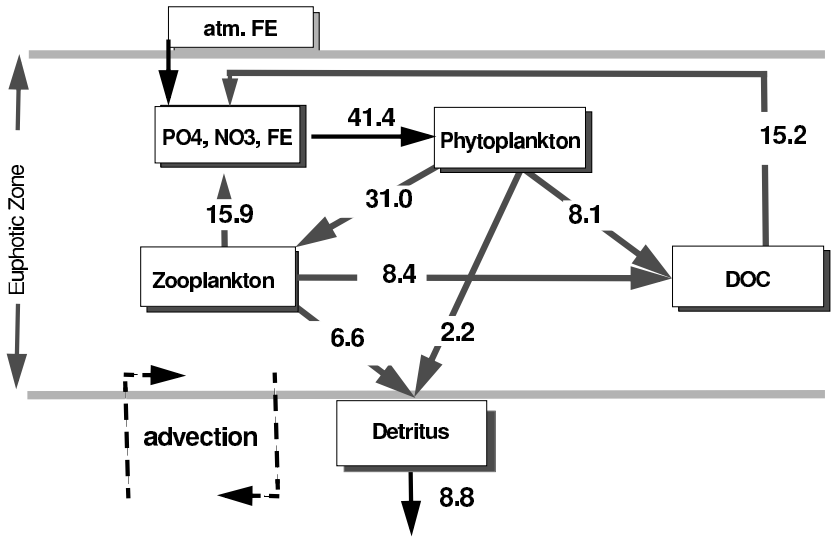

Figure 1. Annual global mean carbon flux between compartments in plankton model within the euphotic zone in $\mathrm{GtC} / \mathrm{yr}$.

primary production of each species is determined as a fraction of the community net production as described by Six and Maier-Reimer [1996] and depends on species abundance, in case of diatoms on silicate concentration and for coccolithophorids on calcification rates. The remaining part of the community net production after subtraction of net primary production from diatoms and coccolithophorids is termed as net primary production of flagellates, which actually describes primary production from a species mixture of heterogeneous size and taxonomy including flagellates. Flagellates are therefore always abundant, while opal producers are the dominant species only as long as silicate is available [Chipman et al., 1993]. Diatoms are the dominant phytoplankton species, for example, in the Southern Ocean. In the northern latitudes the spring bloom of diatoms is resolved by the model. Despite the simplicity of our model the simulation reproduces a similar diatom pattern as found in a more complex diatom model representation from Aumont et al. [2003] with only a slightly higher relative diatom abundance in the equatorial Pacific in our model. Coccolithophorids are relatively more abundant in the subtropical gyres where low silicate concentrations inhibit diatom growth. South of $50^{\circ} \mathrm{S}$ low temperatures limit the growth of coccolithophorids. However, the coccolithophorids represent only a small fraction of the plankton community (less than 5\%) in our simulations. The calcification rate is adjusted to reproduced the observed vertical alkalinity gradients. Since in our model dissolution of calcite shells is restricted to water that is undersaturated with respect to calcite and, thus, does not occur in surface waters calcite production and the particle flux of calcite shells is likely to be underestimated. The simulated global export ratio of 1:5 for carbon in calcite shells and soft tissue, however, matches the estimate by Broecker and Peng [1982].

\subsection{Modeling DMSP and DMS}

[11] The prognostic equations describing dDMSP and DMS turnover follow considerations of the work done by Archer et al. [2002a], Léfevre et al. [2002] and Gabric et al. [1993a]. A schematic diagram of the simulated sulfur components and the flux processes is given in Figure 2. The following equations give an overview of the simulated processes, which are subsequently described in detail.

$$
\begin{gathered}
\frac{\partial D M S P}{\partial t}=\nabla(D M S P)+\epsilon_{D M S P} \cdot Q_{\text {phyto }}-S_{b a c_{D M S P}} \\
\frac{\partial D M S}{\partial t}=\nabla(D M S)+\epsilon_{D M S} \cdot Q_{\text {phyto }}+\gamma_{t} \cdot S_{\text {bac }}{ }_{\text {DMSP }}+\gamma_{h} \cdot Q_{\text {phaeo }} \\
-\gamma_{b} \cdot S_{\text {bac }}-\gamma_{p M S} \cdot S_{\text {photo }}-S_{\text {gas }} .
\end{gathered}
$$

[12] The dDMSP and DMS are transported by the hydrodynamical fields $(\nabla(D M S P), \nabla(D M S))$ identically to nutrients or inorganic carbon. Degradation of phytoplankton is a source for dDMSP and DMS $\left(Q_{\text {phyto }}\right)$. Bacterial activity removes dDMSP $\left(S_{b a c_{D M S P}}\right)$ which in part is a source for DMS. A third DMS source in our model is related to activity of Phaeocystis $\left(Q_{\text {phaeo }}\right)$. Bacterial consumption $S_{\text {bac }}$, photolysis $S_{\text {photo }}$ and efflux to the atmosphere $S_{\text {gas }}$ are the considered DMS removal processes whereby $S_{x}$ describes the seasonally and geographically varying pattern of the removal process. $\gamma_{x}$ denotes the removal rate of the individual process and will be optimized to achieve the best fit between simulation and observation.

[13] Intracellular particulate dimethylsulfoniopropionate (pDMSP), produced by phytoplankton, is not explicitly simulated by our model. We assume a constant sulfur to carbon cell ratio which is only species dependent [Keller, 1991]. The physiological state of phytoplankton and stressinduced changes of intracellular DMSP content [Sunda et al., 2002; Stefels, 2000] are hereby neglected. The current knowledge about these processes regulating the intracellular pDMSP concentration is very uncertain [e.g., Simó, 2004] so that a parameterization on global scale is yet not in view. In this preliminary approach we prescribe constant species dependent S:C ratios, $\gamma_{d}$ and $\gamma_{c}$ for diatoms and coccolithophorids, respectively. The $\mathrm{S}: \mathrm{C}$ ratio in flagellates is prescribed as $\gamma_{c} / 2$. The motivation for this choice is: (1) many calcifying phytoplankton species show much higher S:C ratios than flagellates [Keller et al., 1989; Gabric et al., 1993a], (2) the simulated phytoplankton fraction called flagellates is a composite of phytoplankton

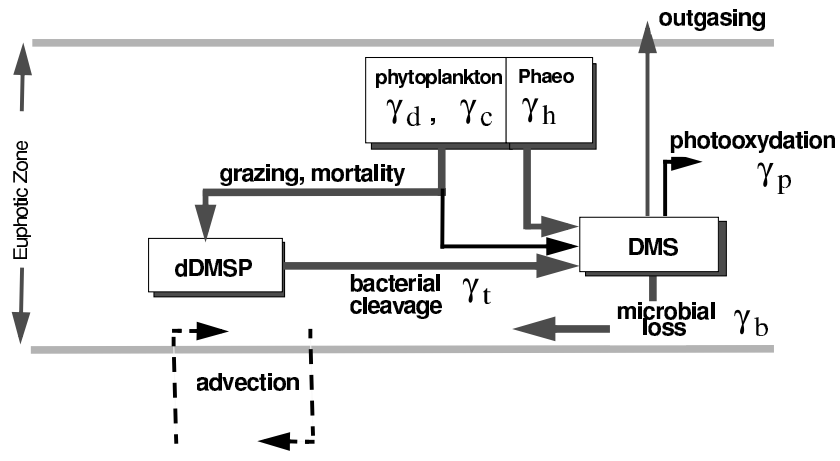

Figure 2. Processes simulated in the sulfur module. Here $\gamma_{x}$ denotes the free parameters which are optimized. 
Table 1. Parameters Used Within the DMS Model

\begin{tabular}{|c|c|c|c|c|}
\hline & Symbol & Unit & Value & Ref. \\
\hline Proportion of dDMSP produced during grazing or by senescence & $\epsilon_{D M S P}$ & 0.6 & & Archer et al. [2002a] \\
\hline Proportion of DMS produced during grazing or by senescence & $\epsilon_{D M S}$ & 0.01 & & Archer et al. [2002a] \\
\hline Temperature constant of bacterial decay & $a$ & $1 /{ }^{\circ} \mathrm{C}$ & 0.033 & Kiene and Bates [1990] \\
\hline Half saturation constant of bacterial decay & $K_{S}$ & $\mathrm{nmol} / \mathrm{L}$ & 0.5 & \\
\hline Maximum Phaeocystis growth rate & $\mu_{\max }$ & $d_{a y}{ }^{-1}$ & 1.3 & Schoemann et al. [2005] \\
\hline Optimal growth temperature for phaeocystis & $T_{o p t}$ & ${ }^{\circ} \mathrm{C}$ & 16.3 & Schoemann et al. [2005] \\
\hline Temperature interval for phaeocystis growth & $d T$ & ${ }^{\circ} \mathrm{C}$ & 13.7 & Schoemann et al. [2005] \\
\hline Half saturation of iron limitation for phytoplankton & $K_{F e}$ & $\mathrm{nmol} / \mathrm{L}$ & 0.033 & \\
\hline
\end{tabular}

being no diatoms or coccolithophorids with rather low $\mathrm{S}: \mathrm{C}$ ratios, and (3) we have to restrict the number of free parameters to a minimum to sustain a reasonable degree of freedom in the model setup.

[14] In general, healthy or growing phytoplankton shows nearly no dDMSP or DMS release to the surrounding sea water [Nguyen et al., 1988]. Recently, there are some indications of DMS lysis in higher level of oxidative stress [Sunda et al., 2002]; this DMS release is not included in our modeling approach. Intracellular pDMSP release occurs mostly through cell autolysis, viral attack or zooplankton grazing, with the latter playing a major role in the initial loss of pDMSP [Simó, 2004]. Therefore the dDMSP and DMS production from phytoplankton degradation is relative to

$$
Q_{\text {phyto }}=\gamma_{d} \cdot G_{D}+\gamma_{c} \cdot G_{C}+\gamma_{c} / 2 \cdot G_{F}
$$

where $G_{D}, G_{C}$, and $G_{F}$ describe the phytoplankton concentration of diatoms, coccolithophorids, and flagellates, respectively, affected by grazing, senescence or exudation within one time step as simulated by the plankton model. Field studies showed that about $60-70 \%$ of the pDMSP ingested by zooplankton is released as dDMSP [Simó and Dachs, 2002; Burkill et al., 2002] and a smaller fraction ( $\leq 3 \%$ ) appears as DMS [Archer et al., 2002a]. We set the fractional release of sulfur from phytoplankton degradation for dDMSP to $\epsilon_{D M S P}=0.6$ and for DMS to $\epsilon_{D M S}=0.01$ (see Table 1 and equations (1) and (2)). We do not account for sulfur assimilated in zooplankton.

[15] Laboratory experiments by Kiene and Service [1991] showed a temperature and substrate (i.e., dDMSP or DMS, resp.) dependency for the bacterial removal of dDMSP and DMS. We describe the bacterial cleavage of dDMSP as

$$
S_{\text {bac DMSP }}=D M S P \cdot f_{\text {bacteria }}(D M S P, T)
$$

with $f_{\text {bacteria }}(D M S P, T)=a \cdot \max (T, 3) \frac{D M S P}{D M S P+K_{S}}$ and, analogously for DMS as

$$
S_{\text {bac }_{D M S}}=D M S \cdot f_{\text {bacteria }}(D M S, T)
$$

with $f_{\text {bacteria }}(D M S, T)=a \cdot \max (T, 3) \frac{D M S}{D M S+K_{S}}$. The linear temperature dependency $a \cdot \max (T, 3)$ is scaled to 1 at surface temperature $T=30^{\circ} \mathrm{C}$. A constant bacterial removal rate below $3^{\circ} \mathrm{C}$ was observed in the studies of Kiene and Service [1991] and is also in agreement with measurements of microbial sulfur consumption in the
Labrador Sea which support a missing correlation between temperature and sulfur consumption at temperatures below $5^{\circ} \mathrm{C}$ [Wolfe et al., 1999]. The substrate dependency is based on a Michaelis-Menten kinetics type limitation as in the work of Archer et al. [2004]. We do not explicitly simulate variations of bacteria abundance and we neglect a potential influence of changes in the availability of inorganic nutrients in this preliminary modeling approach.

[16] Only a minor part of $S_{b a c_{D M S P}}$ is cleaved to DMS by bacteria $(\approx 10 \%$ [Archer et al., 2004]) and the conversion rate might depend on biomass and growth rate of the bacterial population [Kiene et al., 2000]. However, we assume a constant conversion rate $\gamma_{t}$ which will be optimized.

[17] A third source for DMS is related to Phaeocystis, a phytoplankton genus with high intracellular DMSP concentrations that is abundant in all oceans [Keller, 1991; Gabric et al., 2001]. High DMS sea water concentrations were observed during Phaeocystis blooms [Gibson et al., 1990; Simó et al., 2000]. Opposite to other phytoplankton species where healthy growing cells show no DMS release, DMS leakage occurs in Phaeocystis blooms. Phaeocystis growth is primarily temperature-dependent and shows a sensitivity to the ambient iron concentration more than to other nutrients [Schoemann et al., 2005]. The fate of Phaeocystis blooms is still on debate [DiTullio et al., 2000], but there seems to be no contribution to carbon export out of the eutrophic layer by Phaeocystis [Schoemann et al. 2005, and references therein]. Therefore, in this preliminary approach, it might be legitimate to represent DMS production by Phaeocystis with a temperature and iron concentration depending function,

$$
Q_{\text {phaeo }}=\frac{\mu(T)}{\mu_{\max }} \cdot \frac{F E}{F E+K_{F e}}
$$

where $\mu(T)$ is a temperature dependent growth function after Schoemann et al. [2005]

$$
\mu(T)=\mu_{\max } \cdot \operatorname{EXP}\left(\frac{-\left(T-T_{\text {opt }}\right)^{2}}{d T^{2}}\right)
$$

$\mu_{\max }$ scales the temperature function to 1 at $T=T_{\text {opt }} . T_{\text {opt }}$ and $d T$ are given in Table $1 . F E /\left(F E+K_{F e}\right)$ describes the effects of iron limitation on Phaeocystis growth and is identical to the iron limitation in the calculation of primary production. $Q_{\text {phaeo }}$ describes the regional and seasonal pattern of the DMS production by Phaeocystis. It is scaled 
by the free parameter $\gamma_{h}$ which determines the strength of the DMS production by Phaeocystis. We are aware of the simplicity of the representation of Phaeocystis in our model and regard this attempt as a very preliminary step.

[18] Besides the removal of DMS by bacterial consumption $\left(S_{\text {bac }}\right)$ photolysis $\left(S_{\text {photo }}\right)$ and atmospheric ventilation $\left(S_{\text {gas }}\right)$ contribute to the turnover of DMS. For many regions the bacterial consumption seems to play a major role in the DMS removal; for example, at a North Sea study site, 77\% of the annual mean DMS removal was related to bacterial activity [Archer et al., 2004]. Recent studies in the Sargasso Sea and the nitrate-rich Antarctic waters attribute photolysis a dominating role in biogeochemical DMS cycling [Toole and Siegel, 2004; Toole et al., 2004]. These water probes taken in the Sargasso Sea and around Antarctica showed very similar characteristics (absorption coefficients, nitrate concentration), but the Sargasso Sea photolysis rate was 13-fold lower than the one obtained from Antarctic water [Toole et al., 2004]. The authors speculate that $\mathrm{OH}$ scavengers and/or the quality of DOM could be responsible for the difference. Moreover they stated that UV-A drives a large percentage of DMS photolysis. Given these unresolved mechanisms driving regional photolysis rates and in the lack of a spectral model we assume the DMS loss by photolysis to be proportional to the incoming net radiation $I_{0}$ [Archer et al., 2004].

$$
S_{\text {photo }}=D M S \cdot f_{\text {light }} \cdot I_{0} / 750
$$

where $f_{\text {light }} \cdot I_{0}$ describes the average radiation level within the mixed layer. If the mixed layer is shallower than the first two layers, we calculate the average radiation level for the underlying layer from the bottom of the MLD to the bottom of the second layer $(100 \mathrm{~m}) . S_{\text {photo }}$ is scaled by $750 \mathrm{~W} \mathrm{~m}^{-2}$, the radiation level for which Brimblecombe and Shooter [1986] measured a maximum photolysis rate of $0.69 d^{-1}$ at sea surface. The maximum photolysis rate $\gamma_{p}$ in equation (2) is a free parameter.

[19] The flux of DMS across the air-sea interface $S_{\text {gas }}$ is calculated as the product of the gas exchange rate and the concentration gradient of DMS between surface water and atmosphere. Since DMS is rapidly oxidized to $\mathrm{SO}_{2}$ in the atmosphere [Feichter et al., 1996; Chin et al., 2000] and atmospheric DMS concentrations are far from equilibrium with seawater [Dacey et al., 1984] we consider only DMS evasion from the ocean. The gas exchange coefficients for DMS are calculated by applying the Nightingale et al. [2000] relationship on the daily wind speed data from the NCEP/NCAR reanalysis [Kalnay et al., 1996]. The Schmidt number for DMS is taken from Saltzman et al. [1993]. The gas exchange coefficient is not considered as a free parameter in the optimization procedure. Compared to the other processes involved in DMS cycling air-sea gas exchange is fairly well understood.

\subsection{Cost Function and Parameter Optimization}

[20] For the optimization of the free parameters we define a cost function $J$ as a measure of the degree of accordance between simulated and observed values. A global DMS data set is collected by Kettle and Andreae [2000] and extended by NOAA (http://saga.pmel.noaa.gov/dms). $J$ is calculated based on model values which are extracted at the same location and time as the observations were taken. Hereby we have to consider the following.

[21] 1. Shelf areas are not well reproduced in our model due to its coarse resolution. Thus we restrict the DMS data set to open ocean data only and exclude all data in water depth less than $400 \mathrm{~m}$. It is interesting to find that in doing so nearly all data above $100 \mathrm{nmol} / \mathrm{L}$ are removed from the DMS data set.

[22] 2. The DMS data set consists of in situ measurements with high spatial, and interannual variations while model results show much smoother horizontal structures and nearly no interannual variability owing to the cyclo-stationary forcing. Consequently, it is impossible to achieve a good agreement between all pairs of observed and modeled DMS concentration simultaneously. To account for this we define a weight function to get a criterion for the spatial and interannual variability: For each model grid box $i, j$ with more than one observation per month $m$, we calculate a monthly mean DMS surface concentration $\overline{D_{i, j, m}}$ and the corresponding standard deviation $\sigma_{i, j, m}$. If

$$
P_{i, j, m}=\frac{\max \left(0,\left(\overline{D_{i, j, m}}-\sigma_{i, j, m}\right)\right)}{\overline{D_{i, j, m}}}
$$

is small, $\sigma_{i, j, m}$ is of the order for $\overline{D_{i, j, m}}$, which results from either a high interannual or a high spatial variability within this grid box. Thermohaline fronts, for example, produce small-scale features in surface nutrient concentrations which result in a high biological patchiness causing a high variability in surface concentration of DMS [Belviso et al., 2000]. The model is not capable to reproduce these small scale features with horizontal extensions less than grid size. $P_{i, j, m}$ give us a measure to view model deficiencies in relative terms of spatial or interannual variability of the data.

[23] The cost function $J$ is defined as

$$
J=\sum_{k}\left(R_{k} \cdot P_{i, j, m}\right)
$$

with

$$
\begin{aligned}
& R_{k}=M_{k} / D_{k} \quad \text { if } \quad M_{k} \geq D_{k} \\
& R_{k}=D_{k} / M_{k} \quad \text { else }
\end{aligned}
$$

where $k$ is the number of observations, $M_{k}$ is the model value extracted from the simulation at the location and time of observation $D_{k}$. If $R_{k}$ is equal 1 , we achieved a perfect agreement between data and model for this observational point. $J$ is calculated from 16554 observations-model pairs. The highest possible agreement between model and observation $J_{0}$ is achieved if for all observational points $R=1$; if scaled by $P_{i, j, m}$ this results in $J_{0}=11714.6$. In 272 cases there is only one observational value within a grid box and a month and, thus, $P_{i, j, m}=1$. For 549 points the scatter $\sigma_{i, j, m}$ is higher than the monthly mean concentration $\overline{D_{i, j, m}}$ which results in $P_{i, j, m}=0$. The minimum of the cost function is found by applying the steepest gradient method within this six-dimensional parameter space spanned by $\gamma_{x}$. 
Table 2. Optimized Parameters of Experiments BASE, NOPH, and PHAEO Presented With Literature Values, If Available

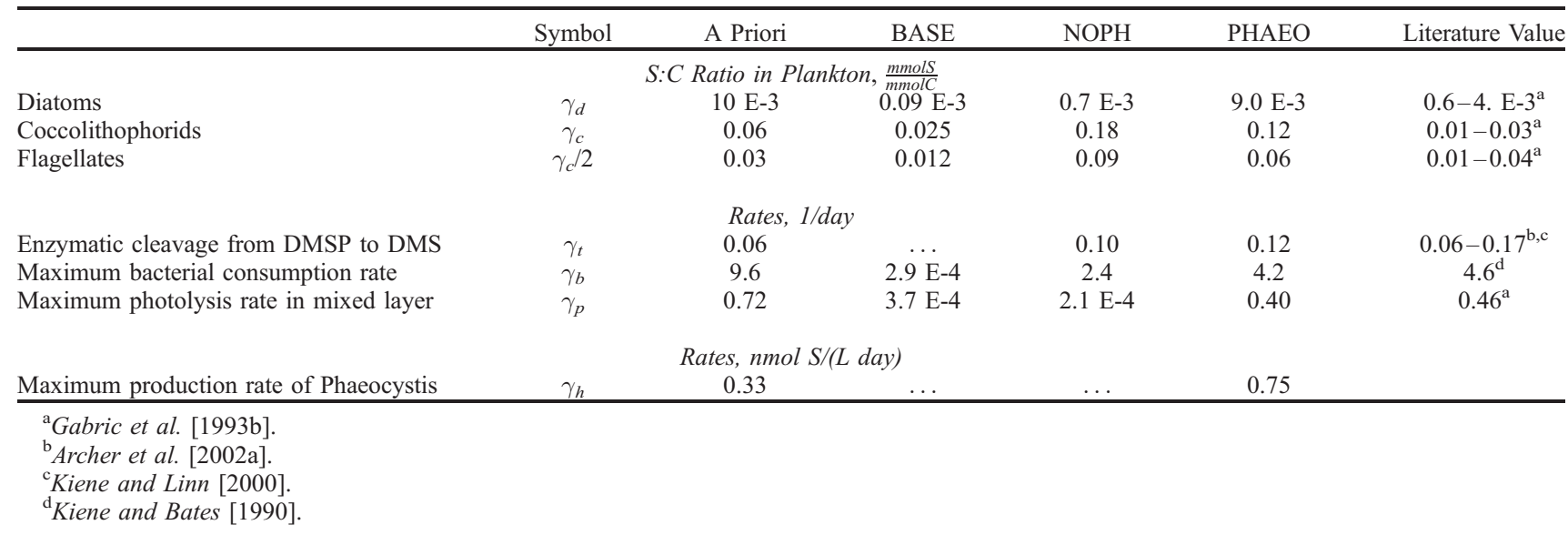

All minimizing problems suffer from the uncertainty of reaching the global minimum. We cannot exclude that our technique leads us only to a local minimum. However, performing a set of sensitivity test with either different starting parameter sets or adding constraints on global turnover rates to the cost function led us to a similar minimum of $J$ and gave us some confidence in the robustness of the results.

\section{Results of Optimization Experiments}

\subsection{General Considerations}

[24] We performed three different experiments to identify the relevance of the assumed processes. The first experiment PHAEO includes all processes described in section 2 by equations (1) and (2). The second experiment NOPH excludes the DMS production by Phaeocystis, thus $\gamma_{h}$. $Q_{\text {phaeo }}=0$ in equation (2). The third experiment BASE further reduces the nonlinearity of the DMS cycle. Here we calculate DMS production directly from the degradation of phytoplankton and exclude the sulfur conversion to $\operatorname{dDMSP}\left(\gamma_{t} \cdot S_{b a c_{D M S P}}=0\right)$ and we assume a globally constant bacterial consumption rate $\gamma_{b}\left(f_{\text {bacteria }}(D M S, T)=1\right)$. Experiment PHAEO reaches the highest degree of accordance between model and data with $J=31129.9$ or $J / J_{0}=2.65$. On the global average all simulated DMS concentrations lie within a factor of 2.65 in the vicinity of the observations. For NOPH we get a ratio of $3.35(J=39285.8)$ and for BASE we yield the worst agreement of only $4.36(J=51159.8)$. In general, for all experiments the model achieves a better agreement to the data in the latitudinal band of $60^{\circ} \mathrm{S}$ and $60^{\circ} \mathrm{N}$. Polar and subpolar regions, especially in the Southern Ocean, show a high variability in the observed DMS concentrations, which is not fully captured by the simulation (data not shown).

[25] The poor result for BASE is not surprising in view of the known complexity of the DMS cycle and the failure of finding a simple regression between phytoplankton concentration and DMS [Kettle et al., 1999; Simó and Dachs, 2002]. Furthermore, the assumption of a constant bacterial consumption rate hinders the simulation of regional and seasonal DMS variations which results in an overestimation of the equatorial DMS concentrations and a concurrent underestimation of DMS in the subtropical gyres. The DMS simulations for the Pacific by Chu et al. [2003] with a 3-D ocean circulation model showed a similar poor reproduction of the latitudinal DMS variability when applying a constant bacterial removal rate.

[26] Table 2 gives the optimized parameters $\gamma_{x}$ of the experiments BASE, NOPH and PHAEO and presents corresponding literature values, if available. The interpretation of the absolute values of the optimization parameters is not straight forward. The parameters might merge several processes like turnover rates of organic material with, for example, $\mathrm{S}: \mathrm{C}$ ratio within cells. In PHAEO $\mathrm{S}: \mathrm{C}$ ratios of diatoms and flagellates are slightly higher than observed. This might indicate that we chose rather too low fractions $\epsilon_{D M S P}$ and $\epsilon_{D M S}$ for the production of sulfur from phytoplankton degradation. However, the simulated $\mathrm{S}: \mathrm{C}$ ratio in coccolithophorids $\gamma_{c}$ is an order of magnitude higher than observed values. As mentioned before the simulated production of coccolithophorids is constrained by the alkalinity export and might be underestimated by neglecting near surface dissolution of calcite shells. The higher than observed $\gamma_{c}$ might indicate that the optimization procedure compensates for this dissolution process. NOPH results in a similar value for $\gamma_{c}$, but weakens the DMS production by diatoms. In BASE the DMS production by coccolithophorids and flagellates additionally is very small, but the parameters controlling DMS removal $\gamma_{t}$ and $\gamma_{p}$ are also much lower than literature values. It is important to note that we put no additional constraints on the range of the optimized parameters. On the basis of the equations describing the DMS cycle the optimization finds a parameter set which achieves the best agreement between the observed and simulated DMS concentrations. The assumed processes in the model can be strengthened or weakened, but their regional and temporal pattern is defined by the assumed equation. In BASE the assumption of an uniform bacterial consumption rate with no regional or seasonal variation and the direct linkage between phytoplankton degradation and DMS production lead to a strong weakening of both, production and 


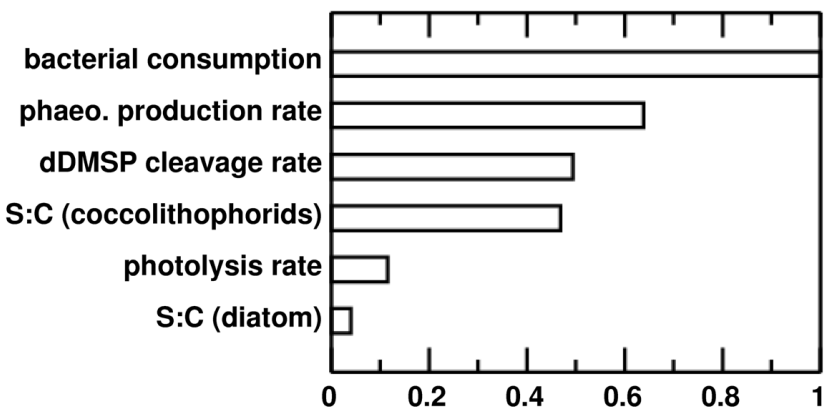

Figure 3. Sensitivity index of the parameters $\gamma_{x}$ to variations of $\pm 5 \%$ relative to the sensitivity of bacterial consumption in PHAEO.

removal processes of DMS, by the optimization resulting in a poor agreement between model and data. The results of BASE are so unsatisfying that BASE will not further be discussed.

[27] In all experiments $\gamma_{d}$ stays small. Timing and amplitude of diatom degradation and thus the corresponding DMS production differs in phasing from observed DMS variations. Therefore the optimization suppresses DMS contributions from diatoms.

[28] The enzymatic cleavage from dDMSP to DMS of $0.12 \mathrm{~d}^{-1}$ and $0.10 \mathrm{~d}^{-1}$ for PHAEO and NOPH, respectively, is within the range of observational estimates. The maximal DMS production rate of Phaeocystis reaches $0.75 \mathrm{nmol} \mathrm{S} /(\mathrm{Ld})$, but we have no possibility to validate this number (see section 4).

[29] The maximum bacterial consumption rate in PHAEO is $4.2 \mathrm{~d}^{-1}$ which is comparable to $4.6 \mathrm{~d}^{-1}$ found by Kiene and Bates [1990] in seawater samples and to $4.18 \mathrm{~d}^{-1}$ used by Archer et al. [2002b] in a North Sea model approach. In NOPH the bacterial consumption rate is only $2.4 \mathrm{~d}^{-1}$ given the lower overall DMS production. In PHAEO the maximum rate of the photolysis is $0.4 \mathrm{~d}^{-1}$ representative for a minimum mixed layer depth of $25 \mathrm{~m}$. It compares well to a rate of $0.46 \mathrm{~d}^{-1}$ given by Gabric et al. [1993b] which is assumed for a surface layer thickness of $20 \mathrm{~m}$. It is striking, that the optimization of the free parameters completely suppresses the process of photolysis in NOPH. As mentioned above the optimization procedure tries to bring the DMS source functions from phytoplankton degradation, Phaeocystis, and bacterial dDMSP consumption and DMS removal functions into line to succeed in a high accordance between model and data. The regional and seasonal pattern of these functions is determined by parameters which are not subject of the optimization. Only the absolute magnitude is optimized by finding $\gamma_{x}$. It seems that in NOPH the phasing in time and space of photolysis does not match the phasing of the DMS source functions (here only from phytoplankton and bacterial dDMSP consumption), i.e., insolation activates photolysis at times when there is only negligible DMS production in NOPH. Thus the optimization suppresses photolysis. In PHAEO the additional production of DMS by Phaeocystis is in phase with a possible degradation by photolysis.

[30] Figure 3 shows the sensitivity of the model results to changes in the optimized parameters. Clearly the system is most sensitive to changes in the bacterial consumption rate for DMS as already shown by other modeling studies [e.g., Le Clainche et al., 2004]. Any increase in the DMS production will be mainly compensated by a higher bacterial consumption rate as observable in PHAEO and NOPH. The production rate of Phaeocystis, the dDMSP cleavage rate, and the $\mathrm{S}: \mathrm{C}$ cell ratio in coccolithophorids show a similar sensitivity. Again our model shows a same sensitive behavior to DMS gross production as other studies [Le Clainche et al., 2004]. Changes in the photolysis rate and the $\mathrm{S}: \mathrm{C}$ ratio of diatoms do not strongly affect the DMS concentration in the current setup.

[31] Figure 4 summarizes the annual mean turnover flux in NOPH and PHAEO. The overall production of DMS is higher in PHAEO, but the additional contribution from Phaeocystis reduces the DMS production from dDMSP cleavage in PHAEO. As already discussed photolysis is negligible in NOPH and it accounts for about $38 \mathrm{Tg} / \mathrm{yr}$ DMS loss in PHAEO. The annual mean air-sea flux of DMS is roughly the same in both experiments. This is plausible, because the air-sea flux is the product of the gas exchange coefficient multiplied by the surface DMS concentrations which are similar in NOPH and PHAEO as a result of the optimization. The annual mean fluxes by photolysis and airsea exchange are of similar order in PHAEO which agrees with observational estimates [Kieber et al., 1996; Archer et al., 2004]. Global mean DMS export from the upper $100 \mathrm{~m}$ by hydrodynamical processes is very small in our model $(0.86 \mathrm{TgS} / \mathrm{yr})$.

\subsection{Seasonal Variability in PHAEO}

[32] In the following we present results from PHAEO only. Before we discuss the DMS surface distributions we
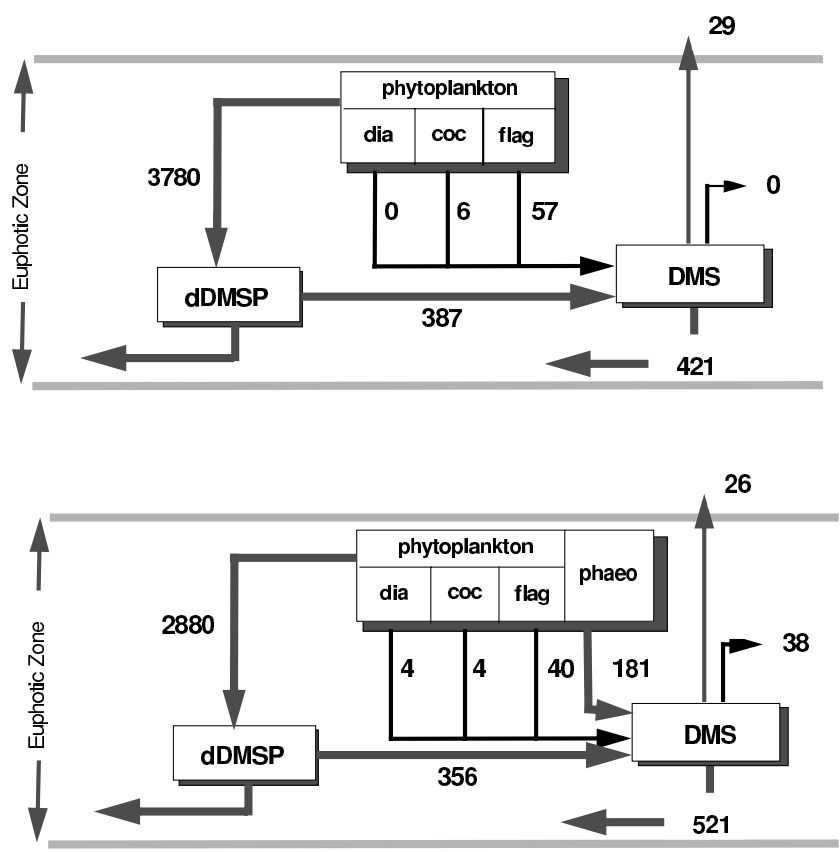

Figure 4. Annual mean sulfur fluxes between compartments of the DMS module in TgS/yr from (top) NOPH and (bottom) PHAEO. See Figure 2 for the legend to the fluxes. 

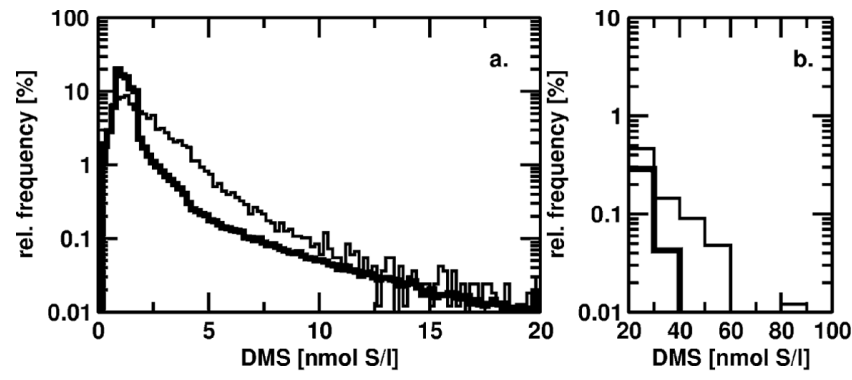

Figure 5. Relative frequency distribution of DMS surface concentrations from the DMS data set and simulations of PHAEO. Frequency is given in logarithmic scaling. (a) Interval taken between 0 to $20 \mathrm{nmol} \mathrm{S} / \mathrm{L}$, increment $0.2 \mathrm{nmol} \mathrm{S} / \mathrm{L}$. DMS data set (thin line), and from PHAEO (thick line) (b) Same as Figure 5a from concentrations above $20 \mathrm{nmol} \mathrm{S/L}$, increment now $10 \mathrm{nmol} \mathrm{S} / \mathrm{L}$. Last increment includes also all values above $100 \mathrm{nmol} \mathrm{S} / \mathrm{L}$.

take a look at the variability of the simulated values (Figure 5). Shown is the relative frequency distribution of the DMS concentrations of the DMS data set and of PHAEO in percent. The frequency distribution of PHAEO is based on DMS surface values from all grid points and all time steps to get an impression of the variability of the simulated concentrations. About $20 \%$ of the concentrations are below $1 \mathrm{nmol} \mathrm{S} / \mathrm{L}$ in the observations and the simulations. The frequency maximum is located between 1 and $1.3 \mathrm{nmol} \mathrm{S} / \mathrm{L}$ for both distributions. However, the frequency distribution of PHAEO shows a narrower peak and less frequent concentrations above $2 \mathrm{nmol} \mathrm{S} / \mathrm{L}$ than found in the observations. There is a similar percentage of observations between 20 and $30 \mathrm{nmol} \mathrm{S} / \mathrm{L}$ in the model $(0.28 \%)$ and in the DMS data set $(0.46 \%)$. Above $30 \mathrm{nmol} \mathrm{S} / \mathrm{L}$ are hardly any DMS concentrations simulated in the model $(0.0001 \%)$ while in the DMS data set $0.3 \%$ of the observations are above $30 \mathrm{nmol} \mathrm{S} / \mathrm{L}$. There might be locally a shift in the phasing of the DMS seasonality, but the model seems to reproduce high and low DMS concentrations in a similar manner as given in the observations. Still, one has to keep in mind that the observations for their part do not represent the full variability of the natural oceanic DMS concentrations [Anderson et al., 2001].

[33] To give an impression of the spatial DMS seasonality we display DMS surface concentration (monthly means) for March, July, October, and December and the observations from the DMS data set for the corresponding month (overlaid boxes) (Figure 6). The sparseness of the observations becomes obvious. In July there is only one observational location (Amsterdam Island, $37.5^{\circ} \mathrm{S} 77.3^{\circ} \mathrm{E}$ ) in the Southern Hemisphere, just as there are hardly any data in the Northern Hemisphere in December. A comparison by eye shows an acceptable agreement between model and data. Simulated DMS concentrations of 2-3 nmol S/L are present in the eastern Equatorial Pacific throughout the year which is also found in the data in July and December. The western equatorial Pacific shows conspicuously low DMS concentrations of less than $0.5 \mathrm{nmol} \mathrm{S} / \mathrm{L}$ in the model. The DMS data show higher concentrations in March (above $2.0 \mathrm{nmol} \mathrm{S} / \mathrm{L}$ ) and July (above $1 \mathrm{nmol} \mathrm{S} / \mathrm{L}$ ). As mentioned before, the model probably underestimates the biological production and thus DMS production in the western equatorial Pacific due to the micronutrient iron which shows very low simulated concentrations of less than $0.02 \mathrm{nmol} \mathrm{Fe} / \mathrm{L}$ in this region.

[34] The subtropical gyres of the Atlantic show slightly higher values $(\geq 1 \mathrm{nmol} \mathrm{S} / \mathrm{L})$ than in the measurements in March and October $(0.5-1.0 \mathrm{nmolS} / \mathrm{L})$. The DMS production of Phaeocystis is simulated as being a function of surface temperature and iron concentration. Both are constantly high in the Atlantic subtropical gyres leading to a year-round DMS production by Phaeocystis.

[35] In the Southern Ocean, high DMS concentrations of more than $20 \mathrm{nmol} \mathrm{S} / \mathrm{L}$ in December are predicted by the model and found in the DMS data set. The observations in the region of the Antarctic Circumpolar Current reveal a

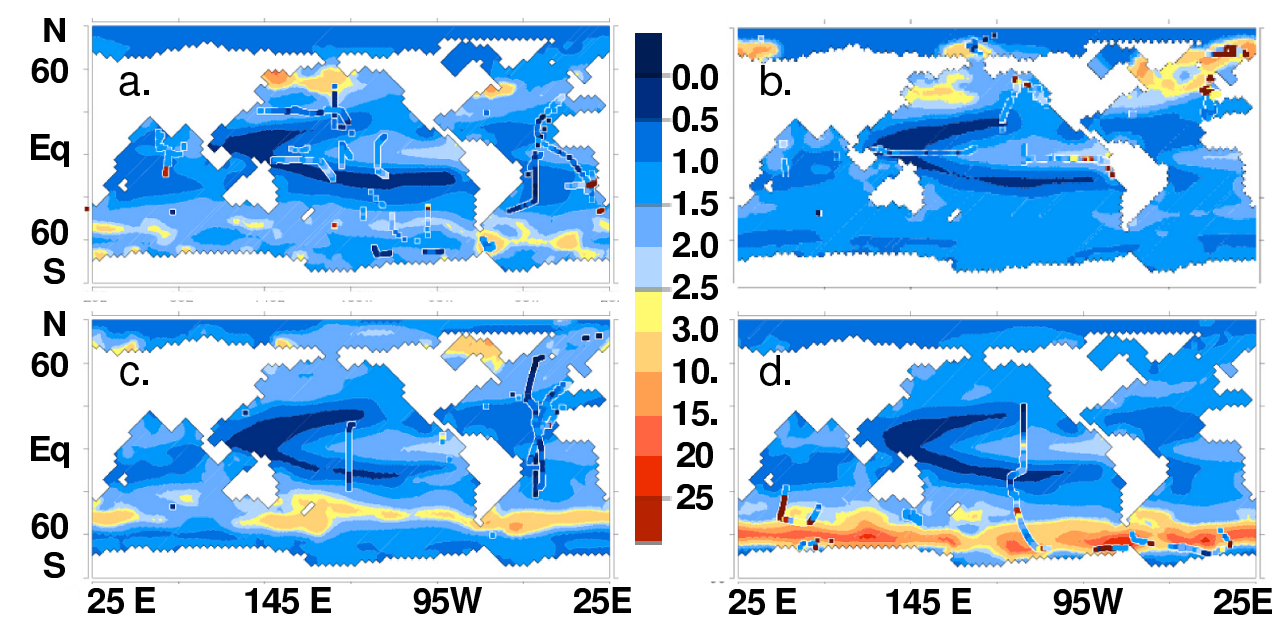

Figure 6. Monthly mean DMS surface concentration from PHAE for (a) March, (b) July, (c) October, and (d) December in nmolS/L. Overlaid are monthly mean of in situ measurements from the DMS data set for the corresponding month and location. 

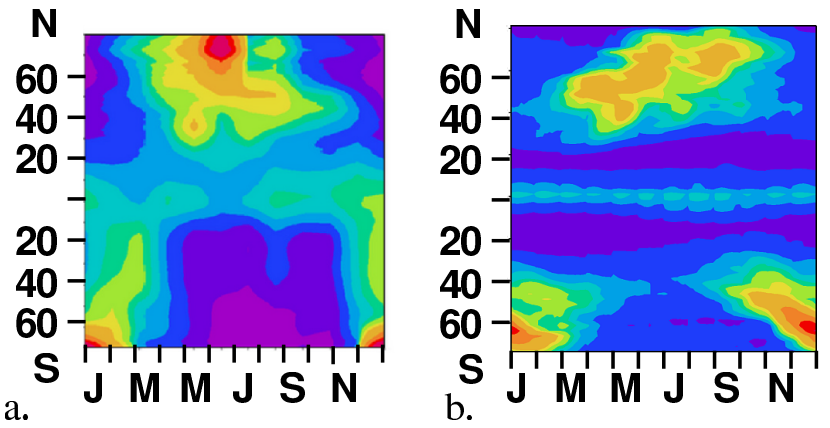

\section{$\begin{array}{lllllllllll}0.5 & 1 & 1.5 & 2 & 2.5 & 3 & 4 & 5 & 10 & 15 & 20\end{array}$}

Figure 7. Time-latitude diagram of zonal mean DMS surface concentration (nmol S/L) from (a) Kettle and Andreae [2000] and (b) PHAEO.

high spatial variability which is not captured to full extent by the model.

[36] The temporal variability of the DMS surface concentrations can also be shown as global zonal mean displayed versus time (Figure 7b). For comparison we display the corresponding figure from Kettle and Andreae [2000], who derived a monthly mean DMS maps by a simple apportioning scheme applied to the global DMS data set. The overall pattern is very similar between both time-latitude diagrams, but the hemispheric winter concentrations in the calculation by Kettle and Andreae [2000] are lower in the subpolar and polar oceans. As mentioned above, we might overestimate the DMS production by Phaeocystis limiting its growth only by temperature and iron. However, the reliability of the estimate by Kettle and Andreae [2000] is reduced due to the sparseness of the DMS data in winter periods (Figure 6). The onset of the DMS production in the Southern Ocean and the amplitude of the seasonal maximum are similar in both time-latitude diagrams. In PHAEO, increasing DMS concentrations are already present in the latitudinal band around $50^{\circ} \mathrm{S}$ in October. This feature is missing in the climatology by Kettle and Andreae [2000], but again, the available measurements are very limited for that zonal band. In the subpolar oceans of the Northern Hemisphere, simulated and observed high DMS concentrations correspond in timing and amplitude. North of $70^{\circ} \mathrm{N}$ the estimate by Kettle and Andreae [2000] shows very high DMS concentrations which are not present in the model. As mentioned before, we use only open ocean data because the coarse resolution of LSG hinders a good representation of shelf areas. The extreme high DMS concentrations present in the Kettle and Andreae [2000] estimate north of $70^{\circ} \mathrm{N}$, all located on polar shelf, are not included in the optimization.

[37] The DMS concentration in the zonal band of the subtropical gyres of the Northern and Southern Hemispheres are much lower in the model than in the estimate of Kettle and Andreae [2000]. The zonal mean in the model is dominated by the unrealistically low DMS surface values simulated in the western Pacific (see Figure 6). Compared to other global DMS estimates [Belviso et al., 2004], our model shows a pronounced latitudinal and seasonal variability.

\subsection{DMS Turnover Rates in PHAEO}

[38] Figure 8 shows the latitude-time plot of the production rate of DMS in nmol $\mathrm{S} /(\mathrm{L} d)$ from bacterial consumption of dDMSP, from Phaeocystis and from direct release by phytoplankton (sum of diatoms, coccolithophorids, and flagellates). The production pattern from direct phytoplankton release and from bacterial consumption of dDMSP are very similar since both follow the pattern of phytoplankton degradation, but the magnitude of the production from bacterial consumption of dDMSP is about a factor 8 higher. A distinct seasonality with high production times in the hemispheric spring and summer months is visible. The production pattern from Phaeocystis follows the temperature pattern combined with the surface iron concentration. Thus we see basically a north-south pattern following the temperature gradient. The simulated production by Phaeocystis is highest in the subtropical gyres of both hemispheres. The low production rate simulated in the western Pacific are covered by the zonal averaging. There are unfortunately no data on DMS production by Phaeocystis to compare to our results. Only the observation of high DMS concentration in the vicinity of Phaeocystis blooms [Gibson et al., 1990], the high cellular DMSP concentrations and the global abundance of Phaeocystis [Whipple and Verity, 2005] indicate their potential role in global DMS production.

[39] The relative zonal mean contributions of the different DMS removal processes are shown in Figure 9 for the

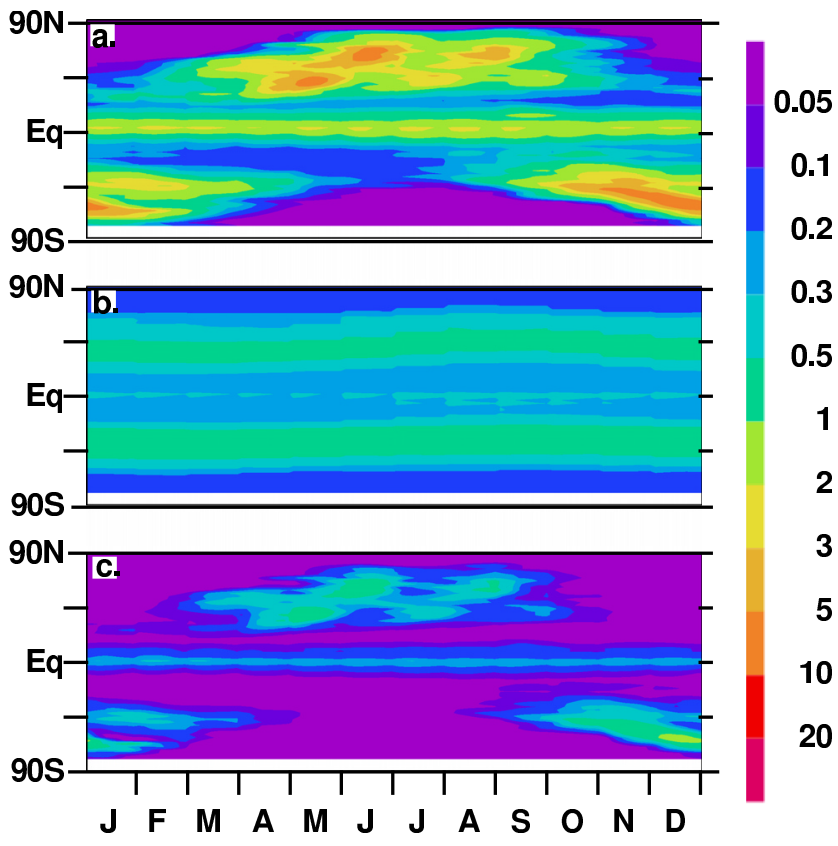

Figure 8. Annual mean production rate of DMS in nmol $\mathrm{S} /(\mathrm{L} \mathrm{d})$, (a) from bacterial consumption of dDMSP, (b) from Phaeocystis, and (c) from direct release by phytoplankton (flagellates, diatoms and coccolithophorids). Levels at $0.05,0.1,0.2,0.3,0.5,1,2,3,5,10,20$. 


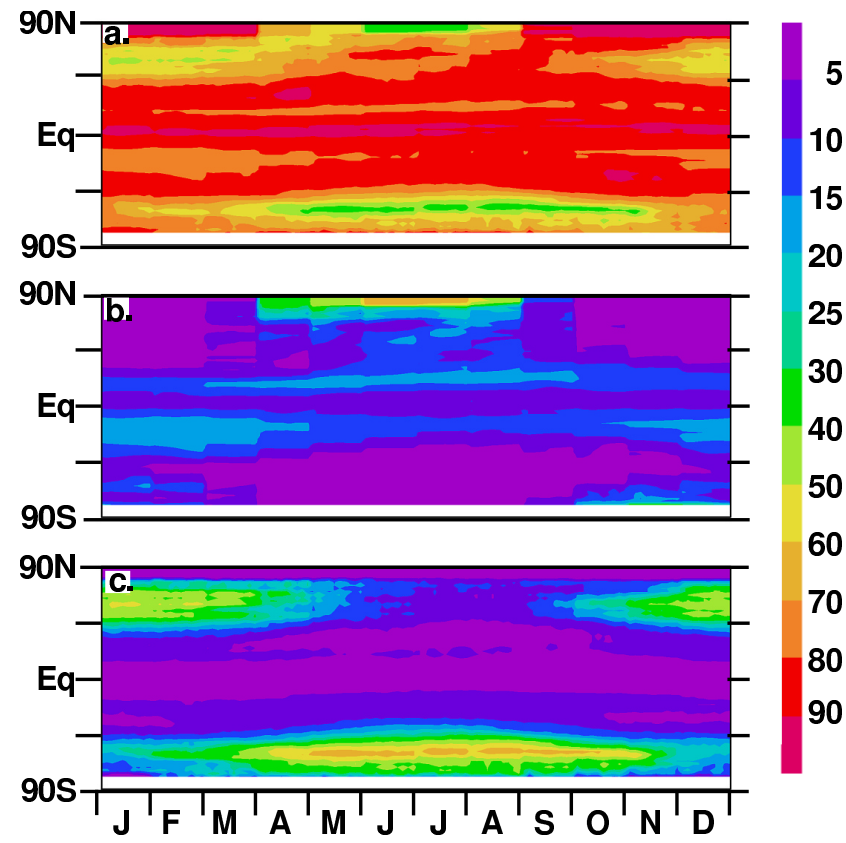

Figure 9. Annual mean relative contribution of (a) bacterial consumption, (b) photolysis, and (c) air-sea exchange to total DMS removal within the surface layer on a percentage basis.

surface layer $(50 \mathrm{~m})$. As already deducible from the annual mean numbers bacterial cleavage removes a significant fraction of DMS in most areas of the world ocean. An exception are the high latitudes where both photolysis and air-sea exchange show a seasonal dependent contribution of up to $60 \%$ to the DMS removal. The air-sea exchange is mainly active in the hemispheric winter with vivid winds but generally lower DMS surface concentrations. The highest contribution from photolysis is found in the northern higher latitudes in spring and summer. Observations by Toole et al. [2004] showed that photolysis can be the dominant loss process for DMS with the beginning spring time in the southern hemisphere. However, Toole et al. [2004] identified extremely high photolysis rate constants, while in our model the bacterial decay rate is rather small due to low temperatures which leads to a relative higher DMS loss by photolysis. Nevertheless, it is obvious that there is a regional and seasonal varying relevance of the individual loss processes even in this very preliminary approach.

\section{Discussion}

[40] The aim of this study was to develop a fully prognostic DMS module to reproduce observed seasonal and regional DMS distributions. In contrast to many other studies, we avoid empirical correlation formulations or regional tuning of relevant parameters. This gives us the guarantee that the module and its parameterization are consistent with the biogeochemical and hydrodynamical conditions even with changing climatic boundary conditions. The final set of turnover rates as well as the simulated
DMS distribution reflect to a satisfying degree the corresponding observations. This was to be expected for the DMS distributions, but it is noteworthy for the turnover rates not being constrained within the parameter space. If the optimized rates fall within the range of observed values it might indicate that the relevant processes are captured by the module. Experiment NOPH clearly demonstrated this interplay between module configuration and resulting parameterization. The suppression of photolysis by the optimization in NOPH gave indications of a missing DMS source. The inclusion of DMS production by Phaeocystis in PHAEO resulted in a more realistic representation of the photolysis rate. PHAEO additionally achieved the best fit between simulations and observation of DMS and the relative frequency distribution of simulated values resembles the observed one.

[41] Our modeling approach shows two relevant processes that control the oceanic DMS cycle: first, bacterial activity by converting dDMSP to DMS and by consuming DMS, and second, the biodiversity of the plankton community, with an important role of Phaeocystis, on the DMS production.

[42] It is interesting that the bacterial dDMSP cleavage rate found by the optimization is only about $12 \%$; that is, the major fraction of produced dDMSP is not converted to DMS in PHAEO. This supports the suggestions of an important second dDMSP removal pathway, namely the demethylation [Kiene et al., 2000; Levasseur et al., 2004].

[43] The introduction of Phaeocystis seems to play a major role on the quality of the results. However, it is additionally the strongest weakness of our approach that we have to rely the DMS production onto a process which is so poorly known and can not be quantified. From NOPH it seems to be obvious that an additional DMS source is needed. If this DMS source comes from Phaeocystis or other Prymnesiophyceae like Chrysochromulina spp. which also show high DMSP/cell ratios [Keller et al., 1989] has to be a future task.

[44] We also have to be aware of the many simplifications which had to be made in the DMS module, partly to keep the model simple and therefore controllable, partly because many processes are only rudimentary known. The module is, for example, not capable to reproduce the "DMS summer paradox" in the Sargasso Sea [Simó and PedrósAlió, 1999] where a decoupling from DMS and its biological precursors pDMSP and dDMSP is observed. It might be that our simplified representation of photolysis based linearly on the incoming radiation is responsible for the module failure. Toole and Siegel [2004] identified a high correlation between observed variations in UV-A and DMS and attributed DOM an important role in the photochemical DMS loss by a still unknown mechanism.

[45] Furthermore, the representation of bacteria is very simplified in this current version. A future task is to simulate prognostic bacteria abundance. The assumption of a constant fraction $\epsilon_{D M S P}$ and $\epsilon_{D M S}$ is only valid as long as the zooplankton composition is not changing. For example, DMS release from grazing by krill is very different than from grazing by salps, which ingest the whole phytoplankton [Kasamatsu et al., 2004]. 
[46] Despite all sceptic on the quality of the module we regard this approach as a preliminary, but promising step toward a prognostic DMS representation in a global ocean circulation model. This is in view of the potential climatic role of DMS a necessary direction to go. The understanding of the marine sulfur cycle definitely needs to be broadened in both field and numerical modeling studies.

[47] Acknowledgments. We thank Silvia Kloster and Jochen Segschneider for vivid discussions and improvements on the manuscript. Further, we thank A. Gabric and one anonymous reviewer for their constructive comments. The work was supported by IRONAGES, contribution EVK2-CT-1999-00031.

\section{References}

Anderson, T. R., S. A. Spall, A. Yool, P. Cipollini, P. G. Challenor, and M. J. R. Fasham (2001), Global fields of sea surface dimethylsulfide predicted from chlorophyll, nutrients and light, J. Mar. Syst., 30, $1-20$

Archer, S. D., F. J. Gilbert, P. D. Nightingale, M. V. Zubkov, A. H. Taylor, G. C. Smith, and P. H. Burkill (2002a), Transformation of dimethylsulphoniopropionate to dimethylsulphide during summer in the North Sea with an examination of key processes via a modelling approach, Deep Sea Res., Part II, 49, 3067-3101.

Archer, S. D., G. C. Smith, P. D. Nightingale, C. E. Widdicombe, G. A Tarran, A. P. Rees, and P. H. Burkill (2002b), Dynamics of particulate dimethylsulphoniopropionate during a Lagrangian experiment in the northern North Sea, Deep Sea Res., Part II, 49, 2979-2999.

Archer, S. D., F. J. Gilbert, J. I. Allen, J. Blackford, and P. Nightingale (2004), Modelling of the seasonal pattern of dimethylsulphide production and fate during 1989 at a site in the North Sea, Can. J. Fish. Aquat. Sci., $61,765-787$.

Aumont, O., S. Belviso, and P. Monfray (2002), Dimethylsulfoniopropionate (DMSP) and dimethylsulfide (DMS) sea surface distributions simulated from a global three-dimensional ocean carbon cycle model, J. Geophys. Res., 107(C4), 3029, doi:10.1029/1999JC000111.

Aumont, O., E. Maier-Reimer, S. Blain, and P. Monfray (2003), An ecosystem model of the global ocean including $\mathrm{Fe}, \mathrm{Si}$, P colimitations, Global Biogeochem. Cycles, 17(2), 1060, doi:10.1029/2001GB001745.

Belviso, S., R. Morrow, and N. Mihalopoulos (2000), An Atlantic meridional transect of surface water dimethyl sulphide concentrations with 10 $15 \mathrm{~km}$ horizontal resolution and close examination of ocean circulation, J. Geophys. Res., 105(D11), 14,423-14,431.

Belviso, S., L. Bopp, C. Moulin, J. C. Orr, T. R. Anderson, O. Aumont, S. Chu, S. Elliot, M. E. Maltrud, and R. Simó (2004), Comparison of global climatological maps of sea surface dimethyl sulphide, Global Biogeochem. Cycles, 18, GB3013, doi:10.1029/2003GB002193.

Bengtsson, L., E. Roeckner, and M. Stendel (1999), Why is the global warming proceeding much slower than expected?, J. Geophys. Res., 104(D4), 3865-3876

Brimblecombe, P., and D. Shooter (1986), Photo-oxidation of dimethylsulphide in aqueous solution, Mar. Chem., 19, 343-353.

Broecker, W., and T. -H. Peng (1982), Tracers in the Sea, Lamont-Doherty Geol. Obs., Palisades, New York.

Burkill, P. H., S. D. Archer, C. Robinson, P. Nightingale, S. B. Groom, G. A. Tarran, and M. V. Zubkov (2002), Dimethyl sulphide biogeochemistry within a coccolithophore bloom (DISCO): An overview, Deep Sea Res. Part II, 49, 2863-2885.

Chin, M., R. Rood, S. Lin, J. Muller, and A. Thompson (2000), Atmospheric sulfur cycle simulated in the global model Gocart: Model description and global properties, J. Geophys. Res., 105(D20), 24,671-24,687.

Chipman, D. W., J. Marra, and T. Takahashi (1993), Primary production at $47^{\circ} \mathrm{N}$ and $20^{\circ} \mathrm{W}$ in the North Atlantic Ocean: A comparison between the ${ }^{14} \mathrm{C}$ incubation method and the mixed layer carbon budget, Deep Sea Res., 40, 151-169.

Chu, S., S. Elliott, and M. E. Maltrud (2003), Global eddy permitting simulations of surface ocean nitrogen, iron, sulfur cycling, Chemosphere, $50,223-235$

Dacey, J. W. H., S. G. Wakeham, and B. L. Howes (1984), Henry's Law constant for dimethylsulfide in freshwater and seawater, Geophys. Res. Lett., 11, 991-994.

DiTullio, G. R., J. M. Grebmeier, K. R. Arrigo, M. P. Lizotte, D. H. Robinson, A. Leventer, J. P. Barry, M. L. VanWoert, and R. B. Dunbar (2000), Rapid and early export of phaeocystis antarctica blooms in the Ross Sea, Antarctica, Nature, 404, 595-598.
England, M. H., and E. Maier-Reimer (2001), Using chemical tracers to assess ocean models, Rev. Geophys., 39, 29-70.

Feichter, J., E. Kjellstroem, H. Rohde, F. Dentener, J. Leleiveld, and G.-J. Roelofs (1996), Simulations of tropospheric sulfur cycle in a global climate model, Atmos. Environ., 30, 1693-1707.

Gabric, A., C. N. Murray, L. Stone, and M. Kohl (1993a), A model of dimethysulphide production during a phytoplankton bloom, in $D i$ methylsulphide: Oceans, Atmosphere, and Climate, edited by G. Restelli and G. Angeletti, pp. 63-81, Springer, New York.

Gabric, A., N. Murray, L. Stone, and M. Kohl (1993b), Modeling the production of dimethylsulfide during a phytoplankton bloom, J. Geophys. Res., 98(C12), 22,805-22,816.

Gabric, A., W. Gregg, R. Najjar, D. Erickson, and P. Matrai (2001), Modeling the biogeochemical cycle of dimethylsulfide in the upper ocean: A review, Chemosphere, 3, 377-392.

Gibson, J. A. E., R. C. Garrick, H. R. Burton, and A. R. McTaggart (1990), Dimethylsulfide and the alga phaeocystis pouchetti in Antarctic coastal waters, Mar. Biol., 104, 339-346.

Intergovernmental Panel on Climate Change (2001). Climate Change 20001: The Scientific Basis, Contribution of Working Group I to the Third Assessment Report of the Intergovernmental Panel on Climate Change (IPCC), edited by J. T. Houghton et al., Cambridge Univ. Press, New York.

Kalnay, E., et al. (1996), The NCEP/NCAR 40-year reanalysis project, Bull. Am. Meteorol. Soc., 77, 437-471.

Kasamatsu, N., S. Kawaguchi, S. Watanabe, T. Odate, and M. Fkuchi (2004), Possible impacts of zooplankton grazing on dimethylsulfide production in the Antarctic Ocean, Can. J. Fish. Aquat. Sci., 61, 736-743.

Keller, M. D. (1991), Dimethyl sulphide production and marine phytoplankton: The importance of species composition and cell size, Biol. Oceanogr., 6, 375-382.

Keller, M. D., W. K. Bellows, and R. L. Guillard (1989), Dimethyl sulfide production in marine phytoplankton, in Biogenic Sulfur in the Environment, edited by E. S. Saltzman, and J. W. Cooper, pp. 167-181, Am. Chem. Soc., Washington, D. C.

Kettle, A. J., and M. O. Andreae (2000), Flux of dimethylsulfide from the oceans: A comparison of updated data sets and flux models, J. Geophys. Res., 105(D22), 26,793-26,808.

Kettle, A. J., et al. (1999), A global database of sea surface dimethylsulfide (DMS) measurements and a procedure to predict sea surface DMS as a function of latitude, longitude, and month, Global Biogeochem. Cycles, $13,399-444$

Kieber, D. J., J. Jiao, R. P. Kiene, and T. S. Bates (1996), Impact of dimethylsulfide photochemistry on methyl sulfur cycling in the equatorial Pacific Ocean, J. Geophys. Res., 101(C2), 3715-3722.

Kiene, R. P., and T. S. Bates (1990), Biological removal of dimethyl sulphide from seawater, Nature, 345, 702-705.

Kiene, R. P., and L. Linn (2000), Distribution and turnover of dissolved DMSP and its relationship with bacterial production and dimethysulfide in the Gulf of Mexico, Limnol. Oceanogr., 45(4), 849-861.

Kiene, R. P., and S. K. Service (1991), Decomposition of dissolved DMSP and DMS in estuarine waters: Dependence on temperature and substrate concentration, Mar. Ecol. Prog. Ser., 76, 1-11.

Kiene, R. P., L. Linn, and J. A. Bruton (2000), New and important roles for DMSP in marine microbial communities, J. Sea Res., 43, 209-224.

Kurz, K. D. (1993), Zur saisonalen Variation des ozeanischen Kohlendioxidpartialdruck, Ph.D. thesis, Max-Planck-Inst. for Meteorol., Hamburg, Germany.

Le Clainche, Y., M. Levasseur, A. Vézina, J. W. H. Dacey, and F. J. Saucier (2004), Behaviour of the ocean DMS (P) pools in the Sargasso Sea viewed in a coupled physical-biogeochemical ocean model, Can. J. Fish. Aquat. Sci., 61, 788-803.

Léfevre, M., A. Vézina, M. Levasseur, and J. W. H. Dacey (2002), A model of dimethylsulfide dynamics for the subtropical North Atlantic, Deep Sea Res., Part I, 49, 2221-2239.

Levasseur, M., M. Scarratt, S. Roy, D. Laroche, S. Michaud, G. Cantin, M. Gosselin, and A. Vézina (2004), Vertically resolved cycling of dimethylsulfoniopropionate (DMSP) and dimethylsulfide (DMS) in the Northwest Atlantic in spring, J. Fish. Aquat. Sci., 61, 744-757.

Longhurst, A., S. Sathyendranath, T. Platt, and C. Caverhill (1995), An estimate of global primary production in the ocean from satellite radiometer data, J. Plankton Res., 17, 1245-1271.

Maier-Reimer, E. (1993), Geochemical cycles in an ocean general circulation model: Preindustrial tracer distributions, Global Biogeochem. Cycles, 7, 645-677.

Maier-Reimer, E., U. Mikolajewicz, and K. Hasselmann (1993), Mean circulation of the Hamburg LSG OGCM and its sensitivity to the thermohaline surface forcing, J. Phys. Oceanogr., 23, 731-757. 
Nguyen, C., S. Belviso, N. Mihalopoulos, J. Gostan, and P. Nival (1988), Dimethyl sulfide production during natural phytoplankton blooms, Mar Chem., 24, 133-141.

Nightingale, P. D., G. Mallin, C. S. Law, A. J. Watson, P. S. Liss, M. I. Liddicoat, J. Boutin, and R. C. Upstill-Goddard (2000), In situ evaluation of air-sea gas exchange parameterizations using novel conservative and volatile tracers, Global Biogeochem. Cycles, 14, 373-387.

Roeckner, E., L. Bengtsson, J. Feichter, J. Lelieveld, and H. Rodhe (1999), Transient climate change simulations with a coupled atmosphere-ocean GCM including the tropospheric sulfur cycle, J. Clim., 12(10), 30043032 .

Saltzman, E. S., D. S. King, K. Holmen, and C. Leck (1993), Experimental determination of the diffusion coefficient of dimethylsulfide in water, J. Geophys. Res., 98(C9), 16,481-16,486.

Schoemann, V., S. Becquevort, J. Stefels, V. Rousseau, and C. Lancelot (2005), Phaeocystis blooms in the global ocean and their controlling mechanisms: A review, J. Sea Res., 53, 43-66.

Simó, R. (2004), From cells to globe: Approaching the dynamics of DMS (P) in the ocean at multiple scales, Can. J. Fish. Aquat. Sci., 61, 673-684.

Simó, R., and J. Dachs (2002), Global emission of dimethylsulfide predicted from biogeophysical data, Global Biogeochem. Cycles, 16(4), 1018, doi:10.1029/2001GB001829.

Simó, R., and C. Pedrós-Alió (1999), Role of vertical mixing in controlling the oceanic production of dimethyl sulfide, Nature, 402, 396-399.

Simó, R., C. Pedrós-Alió, G. Malin, and J. O. Grimalt (2000), Biological turnover of DMS, DMSP and DMSO in contrasting open-sea waters, Mar. Ecol. Prog. Ser., 203, 1-11.
Six, K. D., and E. Maier-Reimer (1996), Effects of plankton dynamics on seasonal carbon fluxes in an ocean general circulation model, Global Biogeochem. Cycles, 10, 559-583.

Stefels, J. (2000), Physiological aspects of production and conversion of DMSP in marine algae and higher plants, J. Sea. Res., 43, 183-197.

Sunda, W., D. J. Kieber, R. P. Kiene, and S. Huntsman (2002), An antioxidant function for DMSP and DMS in marine algae, Nature, 418, $317-$ 320

Toole, D. A., and D. Siegel (2004), Light-driven cycling of dimethylsulfide (DMS) in the Sargasso Sea: Closing the loop, Geophys. Res. Lett., 31, L09308, doi:10.1029/2004GL019581.

Toole, D. A., D. J. Kieber, R. P. Kiene, E. M. White, J. Bisgrove, and D. A del Valle (2004), High dimethylsulfide photolysis rates in nitrate-rich Antarctic waters, Geophys. Res. Lett., 31, L11307, doi:10.1029/ 2004GL019863

Whipple, S. J. B. C. P., and P. G. Verity (2005), Life cycle of the marine alga phaeocystis: A conceptual model to summarize literature and guide research, J. Mar. Syst., 57, 83-110.

Wolfe, G. V., M. Levasseur, G. Cantin, and S. Michaud (1999), Microbial consumption and production of dimethyl sulfide (DMS) in the Labrador Sea, Aquat. Microb. Ecol., 18, 197-205.

E. Maier-Reimer and K. D. Six, Max-Planck Institute for Meteorology, Bundesstrasse 53, D-20146 Hamburg, Germany. (katharina.six@zmaw.de) 